
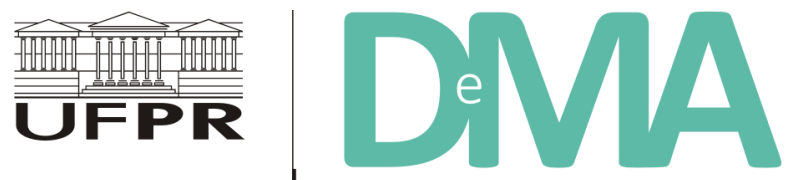

\title{
Socioeconomia da pesca no litoral do estado do Paraná (Brasil) no período de 2005 a 2015
}

\section{Fisheries Socioeconomics on the Coast of the State of Paraná (Brazil) for the Period from 2005 to 2015}

\author{
Jocemar Tomasino MENDONÇA ${ }^{1 *}$, Alineide Costa Mendonça LUCENA ${ }^{2}$, Luiz Danilo MUEHLMANN², \\ Rodrigo Pereira MEDEIROS ${ }^{4}$
}

\author{
${ }^{1}$ Instituto de Pesca, Núcleo de Pesquisa do Litoral Sul, Cananéia, SP, Brasil. \\ ${ }^{2}$ Instituto Bioaustral, Cananéia, SP, Brasil. \\ ${ }^{3}$ Empresa Paranaense de Assistência e Extensão Rural (EMATER), Curitiba, PR, Brasil. \\ ${ }^{4}$ Centro de Estudos do Mar (CEM), Universidade Federal do Paraná (UFPR), Pontal do Paraná, PR, Brasil. \\ *E-mail de contato: jocemar.mendonca@gmail.com
}

Artigo recebido em 8 de novembro de 2016, versão final aceita em 27 de junho de 2017.

RESUMO: A pesca no litoral paranaense constitui atividade tradicional de grande importância econômica e sociocultural, envolvendo um elevado número de pescadores de origem caiçara e açoriana, que tem a pesca como base de sua economia familiar. No entanto, a importância da pesca de pequena escala costuma ser mascarada pela baixa disponibilidade e/ou qualidade das informações. O presente trabalho visa descrever aspectos socioeconômicos da atividade pesqueira do litoral paranaense e as mudanças nas características da atividade, comparando dois períodos num intervalo de onze anos, entre 2005 e 2014/2015. Para a análise, foram utilizados dados socioeconômicos censitários para 2005 e por amostragem para 2014/2015, em todas as comunidades pesqueiras do litoral paranaense. Estimou-se um número de pescadores no litoral paranaense de 5.752 para o período 2014/2015. Houve um incremento na idade média, influenciado pela diminuição do número de ingressos na atividade. A renda média diminuiu no intervalo analisado, resultante da redução da produção e por ter ocorrido menor variação positiva no preço de primeira comercialização dos produtos pesqueiros de áreas estuarinas. Como efeito, houve diferenças de rendimento entre os pescadores do centro-norte e centro-sul paranaense. A pesca manteve suas características predominantemente de pequena escala durante o período analisado, apesar das variações espaciais. Sinais de declínio da atividade foram observados, resultantes da redução do ingresso de pescadores, perdas gradativas no valor agregado aos produtos da pesca e o aumento da dependência em subsídios de políticas públicas (seguro-defeso) para a manutenção da atividade.

Palavras-chave: pesca artesanal; renda dos pescadores; seguro-defeso; renda familiar. 
ABSTRACT: Fishing on the coast of the Paraná is a traditional activity of economically and socio-culturally importance, engaging a large number of fishers from Caiçara and Azorean origin who depend on fishing as their main source of income. Otherwise, importance of small-scale fisheries is undermined by the low availability and/or quality of information. This paper aims to describe the fisheries socioeconomics along the coastal Paraná and the changes in fisheries' characteristics, by comparing two time period twelve years apart, from 2005 and from 2014/2015. Analysis was performed based on survey data and sampling interviews for 2005 and 2014/2015, respectively, with fishers from all fishing communities from the coast of Paraná. The fishers' population was estimated on 5,752 people for the 2014/2015 period. There was an increase in average age influenced by a decrease in newcomers to fishing. The average income reduced along the observed time interval, possibly due to decreased production and lower positive variation in the first price fish products from estuarine areas. As a result, differences between fishers from the north-central and south-central parts of the state were observed. Despite some spatial differences, the profile of small-scale fishing has been preserved during the period analyzed. Declining conditions were also observed, resulted from reduction in new fishers taking up to the fisheries, gradual losses in value chain and the increased dependence on fishing subsides (social benefits in closed seasons).

Keywords: traditional fishing; fishers' income; "seguro-defeso"; family income.

\section{Introdução}

A zona costeira é formada por uma complexa dinâmica social e ecológica, que afeta e é afetada por inúmeras atividades humanas. A pesca, por sua vez, é considerada o principal vetor de transformação dos ecossistemas marinhos (Millennium Ecosystem Assesment, 2005). Da mesma forma, ela representa a principal atividade para inúmeros grupos sociais, gerando empregos e provendo caminhos para a redução da pobreza e promoção da segurança alimentar, especialmente nos países em desenvolvimento (Andrew et al., 2007; FAO, 2005; Jentoft et al., 2011).

A importância da pesca, especialmente aquela de pequena escala, muitas vezes é mascarada pela baixa disponibilidade e/ou qualidade das informações (Diegues, 2006; Berkes et al., 2006). Tal condição ocorre pela dinâmica complexa dos sistemas pesqueiros artesanais (Mahon et al, 2008; Vincent et al., 2007), mas também pela baixa priorização e destinação de recursos e políticas para o setor (Caldeira \& Pierri, 2014). No Estado do Paraná, a complexidade social e ecológica — através da mistura de culturas pesqueiras e urbanas, bem como diversos ambientes aquáticos e terrestres existentes na região — associada à presença de sistemas estuarinos e águas costeiras, promove grande diversidade de sistemas pesqueiros (Andriguetto-Filho et al., 2009). Mas, a descontinuidade de programas de monitoramento, com estudos limitados às ações de pesquisa e extensão, dificulta uma real compreensão sobre seu funcionamento, bem como a gestão do uso dos recursos pesqueiros (Caldeira et al., 2016).

O litoral paranaense inclui os municípios de Guaraqueçaba, Antonina, Morretes, Paranaguá, Pontal do Paraná, Matinhos e Guaratuba. E, de acordo com os dados do IBGE (2013), a região apresenta uma população total de 265,4 mil pessoas, perfazendo $2,5 \%$ da população do estado. A pesca no litoral tem sido uma parte importante da economia há mais de duzentos anos (Miguel, 1997 in Borges et al., 2006). Os pescadores distribuem-se 
em cerca de 70 vilas, rurais ou urbanas. A pesca sediada no estado é de pequena escala, podendo ultrapassar os 6.500 pescadores em todo o litoral. Apenas os barcos camaroneiros, baseados no município de Guaratuba, constituem uma pescaria especializada e empresarial (Andriguetto-Filho et al., 2006; Noernberg et al., 2008).

Embora sejam poucos, existem alguns trabalhos que caracterizaram a atividade pesqueira do litoral do Paraná, com dados da frota e aparelho de pesca (Andriguetto-Filho et al., 2006) e aspectos sociais dos pescadores, inferindo sobre a renda média dos pescadores e sua dependência à pesca em todo o litoral (Borges et al., 2006). Andreoli (2007) analisou locais da relação dos pescadores com o ambiente, indicando forte ligação destes com prática conservacionistas, e Fuzetti \& Corrêa (2007) fizeram a análise do perfil de pescadores na Ilha do Mel e influência de atividades paralelas e de complemento de renda. Estudos de estratégias e métodos/técnicas de pesca dos pescadores do litoral, buscando avaliar as escalas de usos dos recursos pesqueiros comuns (Mafra, 2012) e da dinâmica da pesca em si, como a análise da pesca de mugilídeos, por pescarias que utilizaram o arrasto de praia (Pina \& Chaves, 2005) foram desenvolvidos na região.

Trabalhos sobre os impactos ambientais e econômicos que a pesca de arrasto para camarão ocasiona ao ambiente e atividade, associada a fauna acompanhante (Gomes \& Chaves, 2006) e estudos de equipamentos de pesca utilizados no estuário (Possamai et al., 2011), também foram realizados no litoral do Paraná.

O presente trabalho visa analisar as características socioeconômicas da atividade pesqueira no litoral paranaense, através do estudo do perfil dos pescadores em dois períodos diferentes,
2005 e 2015, buscando analisar os fatores que contribuíram para as possíveis mudanças no perfil dos pescadores.

\section{Metodologia}

O trabalho foi desenvolvido no litoral do Estado do Paraná, nos municípios de Guaraqueçaba, Antonina, Paranaguá, Pontal do Paraná, Matinhos e Guaratuba (Figura 1), em dois períodos distintos: dados da EMATER/PR e Fundação Terra em 2005 e dados do Instituto de Pesca (SAA/SP) de 2014 e 2015.

Em 2005, as coletas de dados foram realizadas pela Empresa Paranaense de Assistência e Extensão Rural - EMATER-PR, vinculada à Secretaria de Agricultura e do Abastecimento do Estado do Paraná (SEAB) e a Fundação Terra (OSCIP ligada ao desenvolvimento rural). Estas instituições, com seu corpo técnico, realizaram o censo da pesca através do registro de todas as comunidades pesqueiras dos municípios do litoral paranaense. Os pescadores foram identificados quando possuíam o documento de registro de pescador (RGP), emitido pela Secretaria Especial de Aquicultura e Pesca da Presidência da República (SEAP/PR). Posteriormente, foi realizada uma entrevista para obter informações socioeconômicas e pesqueiras.

Em 2014 e 2015, as coletas de dados foram realizadas pelo corpo técnico do Instituto de Pesca - IP através do projeto de Caracterização Socioeconômica da Atividade pesqueira e Aquícola do Litoral Paranaense, vinculada à Secretaria de Agricultura e Abastecimento (SAA) do Estado de São Paulo que realizou uma amostragem dos pescadores (com ou sem RGP) em todas 
as comunidades onde houvessem pescadores, conforme apontadas no censo de 2005.

No estudo da pesca, desenvolvido pela EMATER/PR e Fundação Terra, em 2005 foram realizadas 5.315 entrevistas, através do censo pesqueiro em todos os municípios do litoral paranaense. No estudo do Instituto de Pesca em 2014/2015, foram realizadas 1.244 entrevistas nos municípios do litoral paranaense, com entrevistas amostrais em todas comunidades pesqueiras destes municípios apontadas no estudo de 2005.

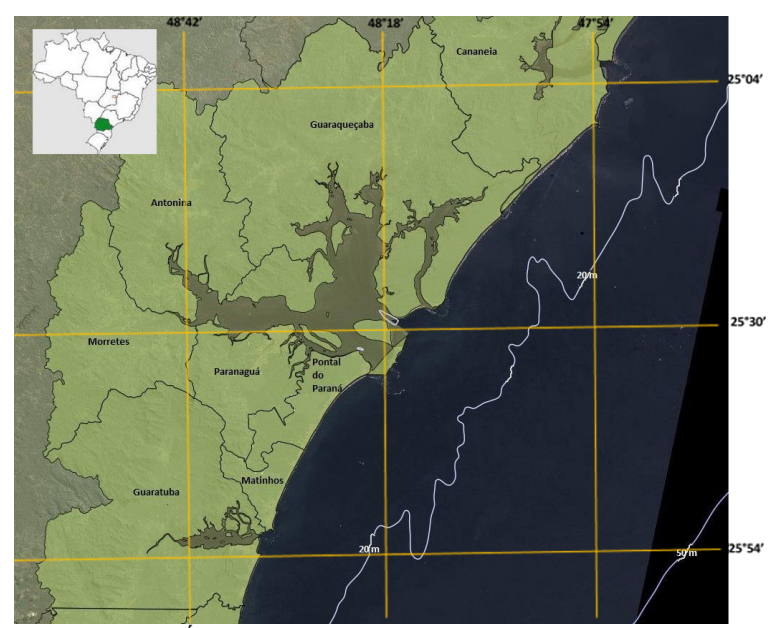

FIGURA 1 - Área de estudo. Municípios do litoral do Estado do Paraná: Guaratuba, Antonina, Paranaguá, Pontal do Paraná, Matinhos e Guaratuba

Em 2014/2015 o trabalho foi amostral, teve como base a percentagem de contribuição no número de pescadores por comunidade em cada município em 2005 extrapolado para o número total de pescadores em 2012, obtido através do Registro Geral do Pescador de 2012 (RGP) do Ministério da Pesca e Aquicultura (MPA, 2013). Tendo esta estimativa por comunidade, foi deter- minado um esforço amostral mínimo de $20 \%$ dos pescadores em cada município e comunidade. Os dados foram coletados através de entrevistas semiestruturadas aos pescadores em todas as comunidades, sendo que, muitas vezes, ultrapassa a percentagem de entrevistas de $20 \%$, assim buscando o maior número possível. Este número mínimo é descrito na literatura como minimamente suficiente para trabalhos de caracterização socioeconômica (Barbetta, 2006).

Para estimativa total de pescadores no litoral e município, foi calculada a porcentagem de pescadores com e sem RGP, aplicando esta proporcionalidade ao número total de cadastros no RGP, obtendo uma estimativa de número total de pescadores no litoral paranaense.

Para a análise de 2014/2015, os municípios dotados de grande área urbana, têm por característica a perda do conceito de comunidade pesqueira. Nestes casos, comunidades são muitas vezes englobadas em bairros vizinhos de uma grande mancha urbana contínua. Para evitar a associação direta entre o conceito de comunidade a um bairro existente - o que levaria à necessidade de analisar dezenas de bairros de forma independente,optou-se por aglutinar bairros em grandes unidades de características similares para fins de análise, a qual chamamos neste artigo de localidade pesqueira. Entretanto, salienta-se que todos os bairros/comunidades foram visitados e devidamente registrados, tendo suas coordenadas de posicionamento geográfico obtidas.

Dados secundários, relativos ao setor pesqueiro, foram obtidos a partir de consultas às bases do MPA (número de pescadores registrados no RGP em 2012). Através do Portal da Transparência, obteve-se o número total de seguros defeso por 
município no período de 2011 a 2014 (Controladoria Geral da União, 2016).

Para análise dos dados entre os períodos de registro foram utilizados o teste " $\mathrm{t}$ " entre as médias da idade, renda (número de salários) e embarcação própria; e o teste do Qui-quadrado $\left(\chi^{2}\right)$, para comparação entre as proporções da escolaridade e dependência da pesca (ocupação principal). Ambas análises tiveram o nível de significância $(\alpha)$ de $5 \%$. A renda média dos pescadores nos municípios foi analisada através do teste de Tukey-Kramer para indicar em quais municípios existem diferenças significativas entre as médias encontradas, para um grau de significância $(\alpha)$ de 5\% (Callegari-Jacques, 2004).

\section{Resultados}

O trabalho de 2005, foi desenvolvido de forma censitária buscando entrevistar todos os pescadores que possuíam RGP. Em 2014/2015 o trabalho foi desenvolvido de forma amostral em cada localidade, por isso há diferença de número de entrevistas realizadas. Em 2005 foram registradas 175 comunidades nos municípios, sendo que Guaraqueçaba e Paranaguá apresentaram maior número. Em 2014/2015, o número de localidades pesqueiras registradas no litoral paranaense foi de 144 , sendo que houve uma redução de 17,7\% em relação a 2005 (Tabela 1).Esta redução foi acarretada por dois fatores: pela aglutinação de comunidades muito próximas em uma única localidade e pelo não encontro de pescadores em 2014/2015 nas comunidades registradas durante o censo.

Dentro destes municípios foram registrados, em 2005, 5.315 pescadores ativos e no estudo em
2014/2015 foi obtido um total de 4.817 - através da consulta ao RGP em 2012 (Tabela 1). Durante o censo de 2005, as entrevistas foram direcionadas aos pescadores regularizados, já no levantamento de 2014/2015 os pescadores foram entrevistados independente de terem registro, apenas verificando se exerciam a atividade. Em geral, os pescadores do litoral paranaense apresentaram RGP, sendo que a grande maioria possui a categoria de pescador artesanal (Tabela 2).

Através das entrevistas, foi possível estimar o número de pescadores sem registo, conforme mostra a tabela 2. Esta informação e a do número total cadastrado no RGP em 2012, possibilitou a estimativa do número total de pescadores no litoral paranaense independe do registro, totalizando 5.752 pescadores nos seis munícipios estudados em 2014/2015. Desta maneira, houve uma diferença de $8,2 \%$ a mais de pescadores no período de 2014/2015, não sendo significativa. Mas, cabe salientar que esta diferença não significativa pode ter sofrido distorção, pois em 2005 as entrevistas foram direcionadas a pescadores com RGP, não incluindo pescadores não registrados.

As localidades com maior número de pescadores em cada município em ambos períodos foram:

Guaraqueçaba: Superagui, com 18,5\% e $19,1 \%$ dos pescadores do município, em 2005 e 2015, respectivamente; Costão (13,0\% e 13,3\%), Cerquinho (8,8\% e 9,0\%), Vila de Almeida (8,5\% e $8,7 \%$ ) e Vila de Ilha Rasa (5,0\% e 5,1\%);

Antonina: Portinho, com $37,1 \%$ e $37,2 \%$ em 2005 e 2015, respectivamente, Ponta do Pita (14,2\% e $14,2 \%)$, Itapema $(8,8 \%$ e $9,0 \%)$, Centro $(3,2 \%$ e $8,8 \%)$ e Tucunduva $(8,8 \%$ e $8,8 \%)$. Paranaguá: Ilha dos Valadares, com 22,7\% em ambos períodos 
TABELA 1 - Número localidades e pescadores pelo censo 2005 e número de localidades e entrevistas na amostragem de 2014/2015 por município.

\begin{tabular}{|c|c|c|c|c|c|c|}
\hline \multirow[b]{2}{*}{ Município } & \multicolumn{2}{|c|}{$\begin{array}{c}\text { Estudo } 2005 \\
\text { EMATER/PR }\end{array}$} & \multicolumn{2}{|c|}{$\begin{array}{l}\text { Estudo 2014/2015 } \\
\text { Instituto de Pesca }\end{array}$} & \multirow[b]{2}{*}{$\begin{array}{c}\mathrm{N}^{0} \mathrm{de} \\
\text { pescadores } \\
\text { (RGP - } \\
\text { 2012) }\end{array}$} & \multirow[b]{2}{*}{$\begin{array}{c}\% \text { de } \\
\text { diferença } \\
\text { das } \\
\text { localidades }\end{array}$} \\
\hline & $\begin{array}{c}\mathrm{N}^{0} \mathrm{de} \\
\text { localidades }\end{array}$ & $\begin{array}{c}\mathrm{N}^{\mathbf{o}} \mathrm{de} \\
\text { pescadores }\end{array}$ & $\begin{array}{c}\mathrm{N}^{0} \text { de } \\
\text { localidades }\end{array}$ & $\begin{array}{c}\mathbf{N}^{\circ} \text { de } \\
\text { entrevistas }\end{array}$ & & \\
\hline Guaraqueçaba & 51 & 2016 & 38 & 385 & 1365 & $-25,5$ \\
\hline Antonina & 28 & 809 & 26 & 225 & 1001 & $-7,1$ \\
\hline Paranaguá & 36 & 987 & 34 & 265 & 993 & $-5,6$ \\
\hline Pontal do Paraná & 23 & 551 & 16 & 102 & 346 & $-30,4$ \\
\hline Matinhos & 16 & 212 & 12 & 56 & 196 & $-25,0$ \\
\hline Guaratuba & 21 & 740 & 18 & 211 & 916 & $-14,3$ \\
\hline Total & 175 & 5315 & 144 & 1244 & 4817 & $-17,7$ \\
\hline
\end{tabular}

TABELA 2 - Percentual de pescadores com e sem Registro Geral da Pesca (RGP) no litoral do estado do Paraná em 2014/2015. Dados de porcentagem e erro padrão da percentagem $(\% \mathrm{EP})$.

\begin{tabular}{lcccccccccc}
\hline \multirow{2}{*}{ Município } & \multicolumn{2}{c}{ Não informado } & \multicolumn{2}{c}{ Não possui } & \multicolumn{2}{c}{ Artesanal } & \multicolumn{2}{c}{ Industrial } & \multicolumn{2}{c}{$\begin{array}{c}\text { Artesanale } \\
\text { Industrial }\end{array}$} \\
\cline { 2 - 11 } & \% & \%EP & \% & \%EP & \% & \%EP & \% & \%EP & \% & \%EP \\
\hline Guaraqueçaba & & & 11,3 & 2,4 & 88,4 & 2,5 & & & 0,3 & 0,3 \\
Antonina & & & 24,4 & 5,3 & 73,8 & 5,4 & 1,3 & 1,5 & 0,4 & 0,0 \\
Paranaguá & 0,4 & 0,1 & 16,6 & 4,5 & 78,1 & 5,0 & 4,5 & 1,6 & 0,4 & 1,4 \\
Pontal do Paraná & & & 13,7 & 4,7 & 86,3 & 4,7 & & & & \\
Matinhos & & & 5,4 & 7,9 & 94,6 & 7,9 & & & & \\
Guaratuba & & & 15,5 & 4,4 & 81,7 & 5,7 & 1,4 & 0,6 & 1,4 & 2,7 \\
\hline
\end{tabular}

de estudo, Vila Guarani $(14,9 \%$ em 2005 e $14,9 \%$ em 2015), Amparo (8,6\% e 8,5\%), Ilha do Mel (5,8\% e $5,8 \%$ ) e Ilha de São Miguel (com 5,3\% em ambos períodos).

Pontal do Paraná: Shangrilá, contribuindo com $17,2 \%$ tanto em 2005 como em 2015, Itapema $(15,2 \%)$, Carmery (9,3\%), Praia do Leste $(7,3 \%)$ e Barrancos (7,1\%).
Matinhos: Sede, representando $41,7 \%$ dos pescadores tanto em 2005 e 2015, Rio das Onças $(19,2 \%)$ e Riviera $(12,7 \%$ em 2005 e $12,8 \%$ em 2015).

Guaratuba: Piçarras, representando 46,6\% dos pescadores do município, em ambos os anos, Mirim $(13,9 \%)$, Caieiras $(8,2 \%)$, Cohapar $(7,2 \%)$ e Barra do Say $(7,1 \%)$. As localidades de Piçarras e Cohapar 
podem ser interpretadas de forma agregada $(53,8 \%)$, uma vez que possuem características geográficas comuns.

A idade média dos pescadores do litoral paranaense ficou em 44 anos ( $\pm 7,0$ anos) em 2005 e aumentou, significativamente, para uma média 44,8 anos ( $\pm 13,6$ anos) em 2014/2015. Motivado, principalmente, pelo aumento significativo da idade no município de Guaraqueçaba. Em relação ao número de membros na família, em 2014/2015 não foi possível estabelecer o número preciso de pessoas, devido a problemas na condução das entrevistas. Mas, em 2005, o número de pessoas nas famílias dos pescadores ficou entre 3,5 a 4 pessoas (Tabela 3).

Os pescadores do litoral paranaense, em geral apresentaram o ensino fundamental incompleto em ambos os períodos de estudo (Tabela 4). Na análise estatística do grau de escolaridade, entre os períodos foram observadas diferenças significativas em praticamente todos os municípios, com aumento no grau de instrução dos pescadores, exceto Antonina, que apresentou diminuição do grau de instrução.

A renda média dos pescadores apresentou di- minuição significativa entre os períodos de 2005 e 2014/2015. No primeiro, os pescadores apresentaram uma renda média de 2,5 salários mínimos ( $\pm 1,3$ s. m.) e em 2014/2015 esta renda diminuiu para 1,1 salários mínimos $( \pm 0,5 \mathrm{~s} . \mathrm{m}$.), havendo um decréscimo de $56 \%$. O município onde houve maior diminuição foi em Pontal do Paraná, com redução de $62 \%$ na renda mensal do pescador.

No estudo de 2005, os pescadores dos municípios de Pontal do Paraná e Matinhos apresentaram renda média mensal significativamente maior que nos demais municípios.

No período de 2014/2015, foi observada uma diferença entre os pescadores do centro-norte paranaense (Guaraqueçaba, Antonina e Paranaguá) e centro-sul (Pontal do Paraná, Matinhos e Guaratuba), sendo que estes últimos apresentam uma renda significativamente superior (Figura 2).

TABELA 3 - Idade média dos pescadores no litoral do Paraná entre os períodos de 2005 e 2014/2015 e número médio de familiares em 2005. Média com desvio padrão. $(*)$ indica que existe diferença significativa a um $\alpha=0,05$.

\begin{tabular}{lccc}
\hline \multirow{2}{*}{ Município } & Estudo 2005 & Estudo 2014/2015 & Estudo 2005 \\
\cline { 2 - 4 } & Idade média & Idade média & $\mathbf{N}^{\mathbf{0}}$ médio de familiares \\
\hline Guaraqueçaba & $41,7 \pm 6,0$ & $42,7 \pm 14,3 *$ & $3,2 \pm 0,9$ \\
Antonina & $44,6 \pm 7,4$ & $46,0 \pm 12,9$ & $3,2 \pm 0,9$ \\
Paranaguá & $46,4 \pm 6,7$ & $47,8 \pm 13,6$ & $3,6 \pm 1,2$ \\
Pontal do Paraná & $44,3 \pm 6,0$ & $45,9 \pm 13,2$ & $3,5 \pm 0,7$ \\
Matinhos & $42,5 \pm 8,7$ & $43,3 \pm 12,6$ & $3,9 \pm 1,2$ \\
Guaratuba & $44,4 \pm 7,3$ & $43,2 \pm 12,5$ & $3,5 \pm 1,1$ \\
Total & $\mathbf{4 4 , 0} \pm \mathbf{7 , 0}$ & $\mathbf{4 4 , 8} \pm \mathbf{1 3 , 6 *}$ & $\mathbf{3 , 4} \pm \mathbf{1 , 0}$ \\
\hline
\end{tabular}


TABELA 4 - Grau de escolaridade dos pescadores do litoral do Paraná em 2005 e 2014/2015. EP\%: erro padrão da média. Em negrito destacase as maiores percentagens entre o grau de instrução em cada período de estudo.

\begin{tabular}{|c|c|c|c|c|c|c|c|c|c|c|c|c|}
\hline 2005 & \multicolumn{2}{|c|}{ Guaraqueçaba } & \multicolumn{2}{|c|}{ Antonina } & \multicolumn{2}{|c|}{ Paranaguá } & \multicolumn{2}{|c|}{ Pontal do Paraná } & \multicolumn{2}{|c|}{ Matinhos } & \multicolumn{2}{|c|}{ Guaratuba } \\
\hline Analfabeto & 15,2 & 2,0 & 10,1 & 2,8 & 16,0 & 3,1 & 9,7 & 4,3 & 1,9 & 1,0 & 7,7 & 1,7 \\
\hline $\begin{array}{l}\text { Fundamental } \\
\text { incompleto }\end{array}$ & 55,0 & 2,8 & 51,0 & 4,7 & 55,6 & 4,1 & 63,2 & 4,3 & 65,9 & 6,5 & 43,0 & 5,8 \\
\hline Fundamental completo & 18,4 & 1,8 & 29,8 & 3,9 & 24,5 & 3,3 & 11,2 & 1,5 & 19,0 & 4,2 & 39,5 & 4,8 \\
\hline Superior & 0,7 & 0,1 & 0,9 & 2,3 & 0,1 & 0,0 & 1,3 & 0,4 & 0,9 & 0,2 & 0,4 & 0,3 \\
\hline \multirow[t]{2}{*}{$2014 / 2015$} & \multicolumn{2}{|c|}{ Guaraqueçaba } & \multicolumn{2}{|c|}{ Antonina } & \multicolumn{2}{|c|}{ Paranaguá } & \multicolumn{2}{|c|}{ Pontal do Paraná } & \multicolumn{2}{|c|}{ Matinhos } & \multicolumn{2}{|c|}{ Guaratuba } \\
\hline & $\%$ & $\% \mathrm{EP}$ & $\%$ & $\% \mathrm{EP}$ & $\%$ & $\% \mathrm{EP}$ & $\%$ & $\% \mathrm{EP}$ & $\%$ & $\%$ EP & $\%$ & $\% \mathrm{EP}$ \\
\hline Fundamental completo & 16,3 & 4,4 & 15,6 & 4,8 & 20,8 & 4,7 & 21,6 & 5,0 & 21,4 & 4,4 & 26,3 & 5,5 \\
\hline Médio incompleto & 3,9 & 2,6 & 5,8 & 3,8 & 4,5 & 2,0 & 4,9 & 3,1 & 12,5 & 5,3 & 6,6 & 2,3 \\
\hline Médio completo & 7,6 & 1,2 & 6,2 & 4,0 & 6,4 & 1,2 & 15,7 & 4,5 & 16,1 & 6,0 & 11,3 & 2,1 \\
\hline Superior incompleto & 0,8 & 0,4 & & & & & & & & & 0,9 & 0,6 \\
\hline Superior completo & 0,3 & 0,2 & & & & & 1,0 & 0,4 & 1,8 & 0,8 & & \\
\hline Não informou & 0,3 & 0,2 & 0,4 & 0,9 & 0,8 & 0,3 & 2,9 & 1,2 & 1,8 & 2,7 & & \\
\hline
\end{tabular}

Entre os períodos estudados houveram diferenças entre a dependência dos pescadores à atividade pesqueira. Sendo que, em 2005, mais pescadores relataram terem outras atividades econômicas além da pesca, tendo como principais atividades secundárias a prestação de serviços, os benefícios previdenciários (aposentadoria) e atividade relacionadas com a pesca (manutenção de equipamentos e petrechos de pesca, processamento de pescado);

Em 2014;2015, os relatos registrados mostraram que aumentou a dependência dos pescadores a atividade pesquiera de forma significa- tiva em todos os municípios. Sendo que, mais de $70 \%$ dos pescadores têm a pesca como principal atividade econômica (Tabela 5).

Neste período, o beneficiamento de pescados foi a ocupação secundária principal. Outras fontes de renda secundárias importantes citadas incluíram benefícios previdenciários (aposentadorias e pensões). 

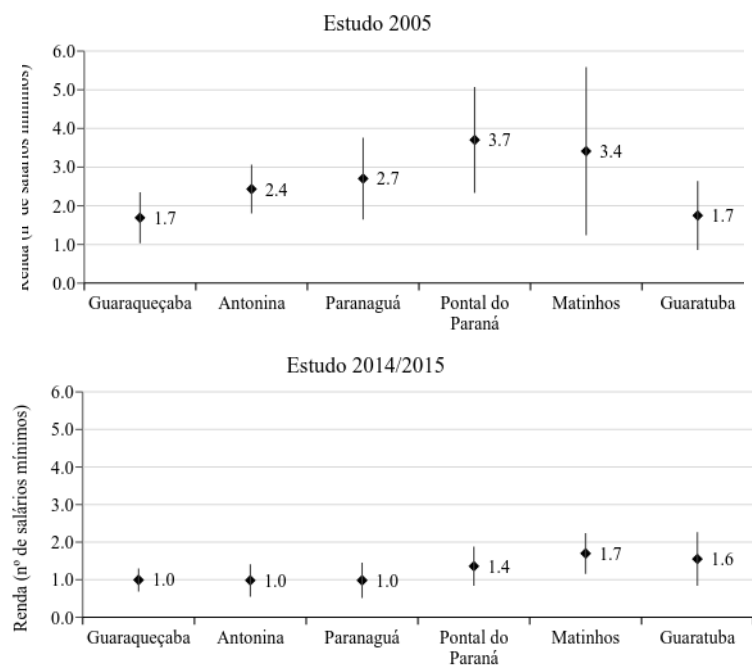

FIGURA 2 - Renda média mensal (com desvio padrão) dos pescadores do litoral paranaense nos períodos de 2005 e de 2014/2015.

Institucionalizada desde 2003, a política de seguro defeso (Lei $\mathrm{n}^{\circ} 10.779,25$ de novembro de 2003, Diário Oficial $n^{\circ}$ 230, Brasília, DF, 26 de novembro de 2003, Seção 1) concede o benefício durante o período de proibição da pesca de determinadas espécies ao pescador profissional que exerce a atividade pesqueira de forma artesanal (Maia, 2009). Nos últimos anos (2011 a 2014), o seguro desefo tem beneficiado em média 3.109 pescadores no litoral paranaense ( \pm 44 pescadores), sendo que, Guaraqueçaba é o município com maior número médio de beneficiados, correspondendo a $34,3 \%$ do total.

De acordo com a estimativa de pescadores no litoral paranaense (5.752 pescadores), foram beneficiados 55,3\% dos pescadores em 2014. O volume anual desembolsado nos seis municípios atingiu uma média de 4,8 milhões de reais $( \pm 521$ mil reais), tendo Guaraqueçaba com o maior aporte (1,6 milhões de reais anualmente) (Tabela 6).

Foram registradas seis normativas que embasam os processos de seguro defeso, em diferentes períodos de parada da pesca. As normativas mais utilizadas são a Portaria IBAMA $\mathrm{n}^{\mathrm{o}} 133$, de 08 de dezembro de 1994 (defeso de camarões nas baías, no período de 15 de dezembro

TABELA 5 - Dependência dos pescadores a atividade pesqueira no período de 2005 e de 2014/2015. EP\%: erro padrão média.

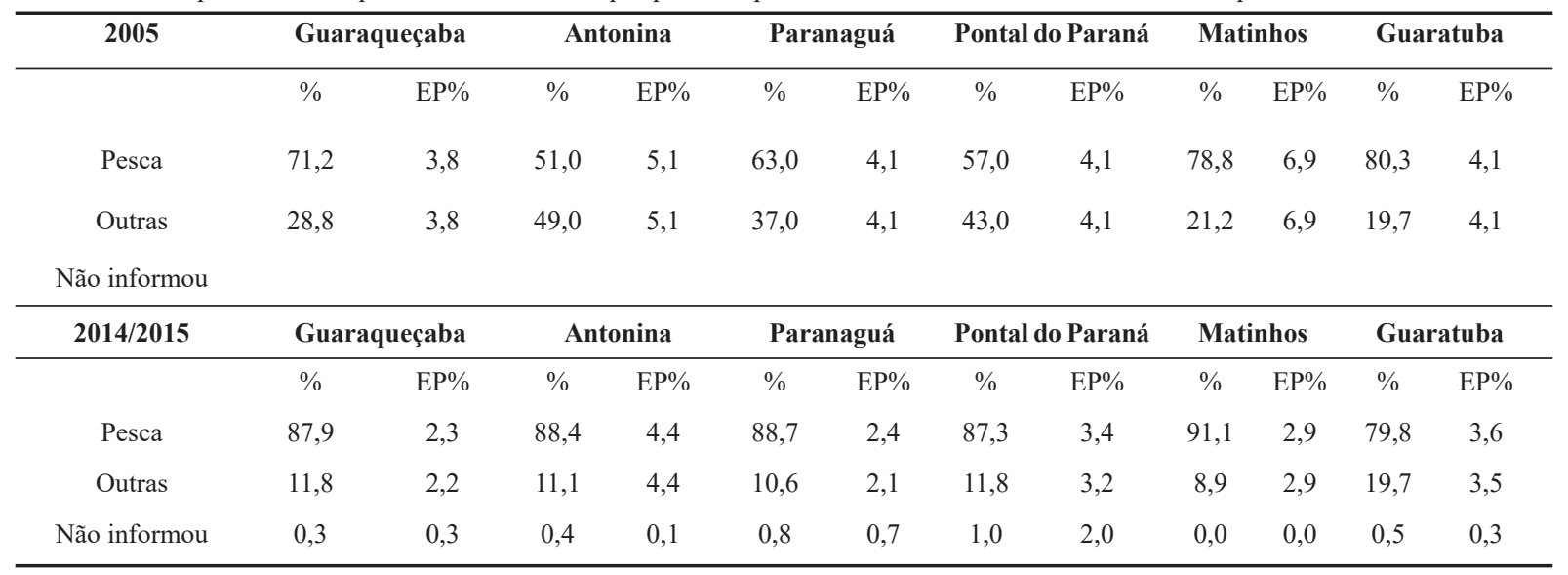


TABELA 6 - Número de pescadores beneficiados e volume desembolsado do seguro defeso no litoral do Paraná no período de 2011 a 2014. Fonte: Portal da Transparência (Controladoria Geral da União, 2016). A percentagem refere-se a participação média de beneficiados ou volume desembolsado no litoral por município no período.

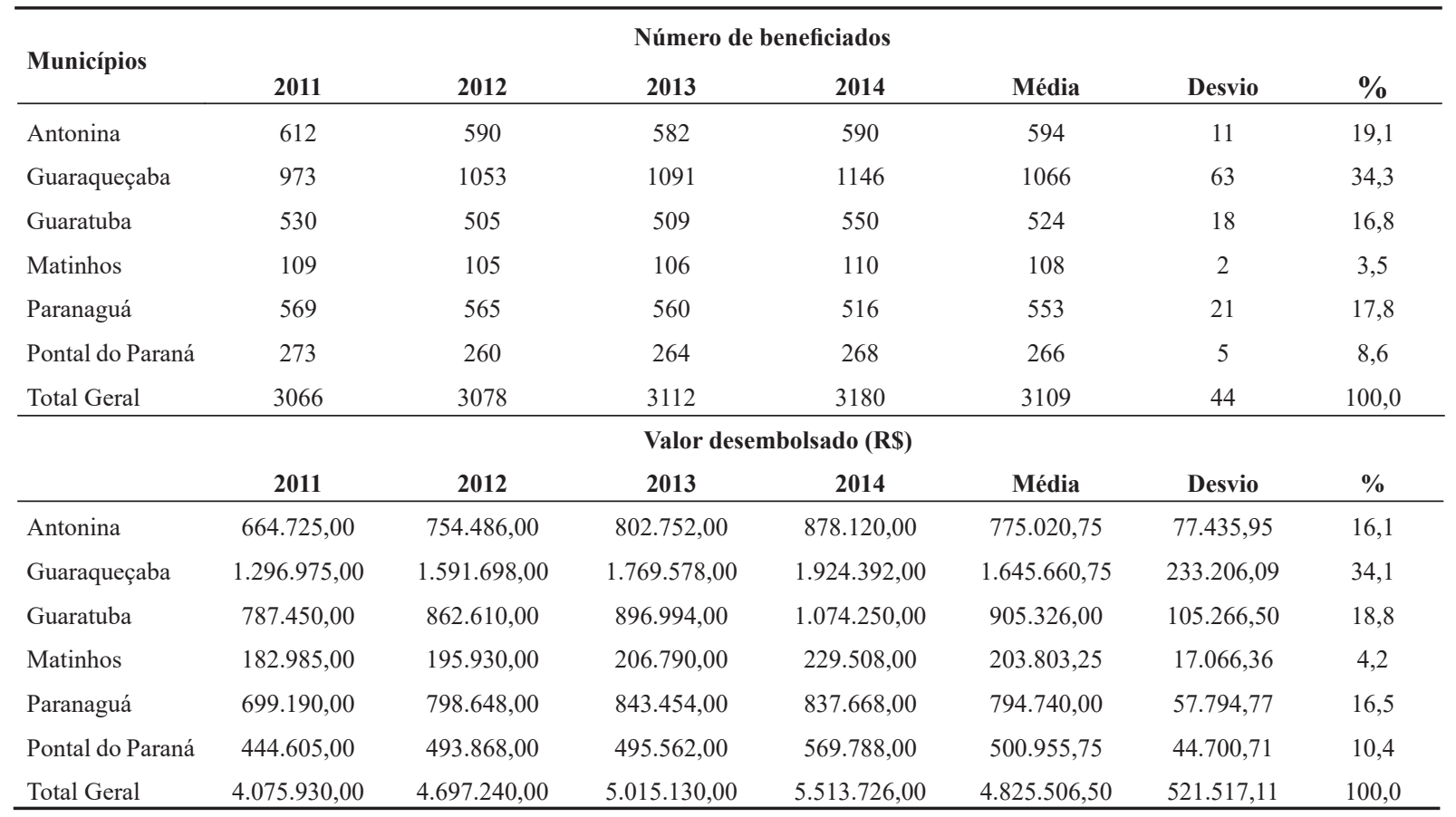

a 15 de fevereiro), e a Portaria IBAMA n ${ }^{\circ} 189$, de 23 de setembro de 2008 (defeso dos camarões na área marinha, no período de 01 de março a 31 de maio), que responderam por $99,9 \%$ dos processos de seguro defeso pagos aos pescadores no período de 2011 a 2014.

\section{Discussão}

A pesca no litoral paranaense é tradicional e envolve um elevado número de pescadores de origem caiçara e açoriana (Silva, 1993: Diegues et al., 2000), que têm a pesca como base de sua economia familiar, além de importante atividade econômica e sociocultural no litoral (Anacleto et al., 2015). O número de pescadores encontrados, tanto em 2005 quanto em 2014/2015, no litoral, foi similar.

Havendo um pequeno aumento de $8,2 \%$ de pessoas entre os períodos, acarretado principalmente pela metodologia aplicada nos diferentes estudos, quando, em 2005, as entrevistas foram direcionadas exclusivamente a pessoas portadoras de carteira de pescador (RGP). Nesta época, já existia uma grande procura de pessoas pela regulamentação 
visando o atendimento do seguro-defeso, praticando ou não a pesca, mas a organização das colônias de pescadores (instituições que encaminham a documentação para registro) não estava adequada para atender o setor na regularização, o que pôde trazer uma subestimação do número de pescadores em 2005. Estes números confirmam os resultados de Andriguetto-Filho et al. (2006), que estimaram o contingente de pescadores em 4.200 pessoas, mas já alertavam que possivelmente o número deveria ser superior.

Atualmente, a grande maioria dos pescadores está registrada junto ao órgão competente, visto que necessitam da documentação para o acesso aos benefícios previdenciários e trabalhistas, tais como a seguridade especial. Cabe salientar que ainda existem discrepâncias entre o número real de pescadores e registros no RGP, principalmente devido a entrada de pescadores para o recebimento apenas do seguro defeso, não tendo a pesca como principal meio de vida. $\mathrm{O}$ que tem gerado muitos questionamentos a esta política pública (Maia \& Pereira, 2010; Mendonça \& Lucena, 2013).

Embora possa ser aparentemente um prazo pequeno de análise (11 anos), observou-se uma tendência significativa de aumento na idade média dos pescadores do litoral, principalmente em Guaraqueçaba. A grande quantidade de pescadores com idade adulta, justifica-se pelo fato de que os mais jovens estão direcionando suas atividades para outros postos de trabalho, que muitas vezes são considerados por eles de maior valia em relação à atividade pesqueira. Então, possivelmente seja real esta tendência, pois existe o incentivo ao estudo dado pelos pais, na atualidade, podendo nortear esses jovens para outra realidade, afastando-os do ambiente pesqueiro (Borcem et al., 2011).
Embora possamos apontar uma diminuição de entrada de pescadores novos na atividade, os que entraram nos últimos 11 anos, em geral, apresentam uma escolaridade maior aos presentes em anos anteriores. Afinal, houve - ao longo do tempo - uma conscientização do pescador em relação à educação dos seus filhos, afastando as crianças do trabalho e estimulando-as a frequentar a escola (Vasconcelos et al., 2003). O acesso dos pescadores ou filhos destes, a rede de ensino nos últimos anos tem sido modificada pela maior viabilidade de transporte ou até mesmo, o maior número de escolas, principalmente no meio rural (Veloso, 2011). Outro fato é que, este aumento da escolaridade também é um reflexo do aumento da escolaridade no país de forma geral. Mas, em contrapartida, a população com idade maior que 40 anos tende a ter menor tempo de escola, pois não tinham este incentivo ou melhor acesso às escolas (Castro, 2009). Embora seja visto de forma salutar, tais fatos colocam em alerta a questão da sucessão da atividade. Quando, por tradição, as técnicas e meios pesqueiros são passados entre as gerações, o que pode não estar mais ocorrendo, visto o não acompanhamento dos filhos aos pais na atividade pesqueira. Fuzetti \& Corrêa (2009), observaram nas comunidades pesqueiras da Ilha do Mel (Paranaguá) que 81\% dos pescadores aprendiam a faina com a prática, junto a família, mas que $93 \%$ não tinham os filhos pescadores.

Em um panorama geral, as famílias dos pescadores do litoral paranaense têm diminuído em número e seus filhos não têm seguido a atividade dos pais, buscando maior instrução e/ou outras atividades produtivas, podendo isto ameaçar a hereditariedade tradicional da atividade.

Entre os dois períodos de estudo (2005 e 
2014/2015), foi observada uma redução geral de $56 \%$ na renda média relativa (i.e. considerada em termos de número de salários mínimos) dos pescadores, tendo o município de Pontal do Paraná a maior redução. Embora não existam dados estatísticos no Paraná para este período, esta queda pode ter ocorrido pela redução da produção desembarcada, diminuindo o rendimento do pescador, visto que os pescadores artesanais do litoral paranaense têm aumentado sua vulnerabilidade ambiental devido à queda na disponibilidade de pescado e a problemas de acesso e gestão dos recursos pesqueiros (Faraco et al., 2016). Caldeira \& Pierri (2014), em Pontal do Paraná, também apontaram o declínio considerável dos recursos pesqueiros desde a década de 1990, fazendo com que extinguisse a pesca de grande escala que existia na época, composta por uma frota motorizada com dimensões de 12 a 18 metros de comprimento, e influenciasse nos rendimentos da pesca de pequena escala, havendo grande redução nas capturas e, por sua vez, no rendimento dos pescadores.

Mas, uma segunda hipótese pode ser formulada, principalmente para os demais municípios, através dos dados de desembarque no estado de São Paulo (estado adjacente ao Paraná). Nos dados do monitoramento pesqueiro de São Paulo (http://www.propesq.pesca.sp.gov.br/relatorio/30, acesso em dezembro de 2015), foi observado que a evolução dos valores pagos ao pescador dos principais produtos pesqueiros, coincidentes com o litoral paranaense, sofreu nos últimos anos aumentos distintos quando consideramos a área de pesca (marinha e estuarina), conforme a Tabela 7.

Andriguetto et al. (2006), caracterizam a pesca dos municípios do litoral paranaense mostrando que os municípios de Pontal do Paraná, Matinhos e Guaratuba têm suas pescarias predominantemente marinhas; enquanto os municípios de Guaraqueçaba, Antonina e Paranaguá, predominam produtos estuarinos. Na tabela 7, observa-se que os produtos marinhos tiveram aumento de 135 a $350 \%$ no valor de comercialização, no período de 2005 a 2015, enquanto nos estuarinos, o aumento no mesmo período foi de 50 a $127 \%$, dependendo do produto. Como a unidade de análise para a renda do pescador é o número de salários mínimos, que teve um incremento de $162,7 \%$ no período de 2005 a 2015 - de acordo com o Ministério do Trabalho e Previdência Social (www.mtps.gov.br) -, observase que os municípios que apresentam pescarias predominantemente marinhas, possivelmente tiveram sua renda diminuída pela queda de produção, como é o caso de Pontal do Paraná, Matinhos e Guaratuba. Já nos municípios onde predomina uma pesca estuariana, os rendimentos tiveram redução, devido - principalmente - à defasagem entre o aumento do salário mínimo e dos produtos predominantes nos seus desembarques, como é o caso de Guaraqueçaba, Antonina e Paranaguá.

Esta hipótese, também explica a diferença significativa entre a renda dos pescadores do centro-norte paranaense (Guaraqueçaba, Antonina e Paranaguá) e centro-sul (Pontal do Paraná, Matinhos e Guaratuba). Os municípios da porção centro-norte paranaense têm sua atividade pesqueira desenvolvida principalmente no estuário, seus produtos pesqueiros tendem a apresentar um valor comercial menor. Nos municípios do centro-sul, onde existe uma predominância de pesca marinha, os produtos pesqueiros são mais valorizados economicamente, fazendo com que a renda dos pescadores destes municípios seja significativa- 
TABELA 7 - Valores médios unitários (R\$) e incremento percentual entre os anos no período de 2005 a 2015 no litoral do Estado de São Paulo. Valores percentuais relativos ao ano de 2005.

\begin{tabular}{|c|c|c|c|c|c|c|c|c|c|c|c|}
\hline \multicolumn{12}{|c|}{ PRODUTOS MARINHOS } \\
\hline & $\begin{array}{l}\text { Valor } \\
\text { médio }\end{array}$ & $\begin{array}{c}\% \\
\text { aumen }\end{array}$ & & $\begin{array}{l}\text { Valor } \\
\text { médio }\end{array}$ & $\begin{array}{c}\% \\
\text { aumento }\end{array}$ & $\begin{array}{l}\text { Valor } \\
\text { médio }\end{array}$ & $\begin{array}{c}\% \\
\text { aumento }\end{array}$ & $\begin{array}{l}\text { Valor } \\
\text { médio }\end{array}$ & $\begin{array}{c}\% \\
\text { aumento }\end{array}$ & $\begin{array}{l}\text { Valor } \\
\text { médio }\end{array}$ & $\begin{array}{c}\% \\
\text { aumento }\end{array}$ \\
\hline 2007 & 2,22 & 42,9 & & 2,19 & 62,7 & 4,74 & 30,6 & 20,48 & 183,3 & 3,29 & 9,5 \\
\hline 2008 & 2,98 & 91,9 & & 2,64 & 96,5 & 4,66 & 28,5 & 20,84 & 188,2 & 4,47 & 48,6 \\
\hline 2009 & 3,79 & 143,8 & & 3,01 & 124,3 & 5,67 & 56,2 & 16,34 & 126,0 & 5,17 & 72,0 \\
\hline 2010 & 4,20 & 170,2 & & 2,93 & 117,8 & 5,66 & 56,1 & 21,95 & 203,6 & 5,42 & 80,4 \\
\hline 2013 & 6,77 & 335,4 & & 4,63 & 244,5 & 7,47 & 106,0 & 24,95 & 245,2 & 6,90 & 129,5 \\
\hline 2014 & 7,06 & 354,5 & & 4,62 & 244,0 & 7,27 & 100,3 & 27,27 & 277,3 & 8,03 & 167,2 \\
\hline 2015 & 7,01 & 350,9 & & 5,00 & 272,3 & 8,55 & 135,8 & 28,95 & 300,5 & 8,10 & 169,4 \\
\hline \multicolumn{12}{|c|}{ PRODUTOS ESTUARINOS } \\
\hline & \multicolumn{2}{|c|}{ Ostra } & \multicolumn{2}{|c|}{ Bagre } & \multicolumn{2}{|c|}{ Tainha } & \multicolumn{2}{|c|}{ Parati } & \multicolumn{3}{|c|}{ Caranguejo-uçá } \\
\hline & $\begin{array}{l}\text { Valor } \\
\text { médio }\end{array}$ & $\begin{array}{c}\% \\
\text { aumento }\end{array}$ & $\begin{array}{l}\text { Valor } \\
\text { médio }\end{array}$ & $\begin{array}{c}\% \\
\text { aumento }\end{array}$ & $\begin{array}{l}\text { Valor } \\
\text { médio }\end{array}$ & $\begin{array}{c}\% \\
\text { aumento }\end{array}$ & $\begin{array}{l}\text { Valor } \\
\text { médio }\end{array}$ & $\begin{array}{c}\% \\
\text { aumento }\end{array}$ & $\begin{array}{l}\text { Valor } \\
\text { médio }\end{array}$ & & \\
\hline 2005 & & & 1,98 & & 3,12 & & 1,27 & & & & \\
\hline 2011 & 3,75 & 48,1 & 3,31 & 67,4 & 4,56 & 46,2 & 1,83 & 43,9 & 3,17 & & \\
\hline 2012 & 4,34 & 71,3 & 3,46 & 74,6 & 5,61 & 79,7 & 2,06 & 62,2 & 2,09 & & \\
\hline 2013 & 2,89 & 14,0 & 3,20 & 61,8 & 6,38 & 104,4 & 1,80 & 42,0 & 3,95 & & \\
\hline 2014 & 3,52 & 39,2 & 2,88 & 45,4 & 7,21 & 131,1 & 2,46 & 94,0 & 5,45 & & \\
\hline 2015 & 3,80 & 50,2 & 3,10 & 56,4 & 7,10 & 127,6 & 2,52 & 98,7 & 5,41 & & \\
\hline
\end{tabular}

FONTE: Instituto de Pesca - APTA/SAA (http//www.propesq.pesca.sp.gov.br). 
mente mais alta, mesmo com menor produção.

A forma de comercialização também pode ser considerada como um fator de diferença na renda dos pescadores, pois, municípios mais turísticos, onde os pescadores apresentam possibilidade de comercialização direta ao consumidor, que neste caso seriam os turistas, tendem a obter valores maiores dos produtos pesqueiros. Andriguetto-Filho (2009), coloca que nas comunidades pesqueiras onde as oportunidades para as atividades alternativas são maiores, tais como comunidades próximas a cidades ou expostas ao turismo, é esperado que a renda familiar seja maior, visto o aumento das oportunidades de serviços, bem como a venda de produtos pesqueiros ao setor turístico. Os pescadores da Ilha do $\mathrm{Mel}$, perceberam grande variação de renda ao longo do ano por consequência da disponibilidade de pescado e do turismo (Fuzetti \& Corrêa, 2009). No verão, quando o número de turistas aumenta, vários produtos pesqueiros podem ser vendidos diretamente aos consumidores por valores maiores, e a prestação de serviços aos turistas também contribui para o aumento da renda da população local. Observa-se, portanto, maiores oportunidades de incremento da renda quando há maior disponibilidade de consumidores e quando os pescadores assumem maior controle da cadeia produtiva, encurtando a distância entre a primeira comercialização e o consumidor final.

Observou-se a predominância da pesca de arrasto, com o uso de embarcações menos equipadas. Essa frota tem se sustentado apesar da diminuição dos recursos pesqueiros. Os rendimentos são menores quando comparados a pescadores cujas estratégias baseiam-se na diversificação dos aparelhos de pesca. Estratégias de pesca baseada na diversificação de pescarias promovem renda aproximada de um salário mínimo mensal (Caldeira \& Pierri, 2014), valores nem sempre atingidos na frota de arrasto, uma vez que para esta o rendimento baseia-se numa menor variedade de produtos e com valores comerciais mais baixos.

Desde meados da década de 1980, o setor pesqueiro tem entrado em crise, acarretando a necessidade das famílias pescadoras artesanais diversificarem suas fontes de renda, forçando a pluriatividade ou mesmo o abandono da pesca (Mendonça, 2015). Contraditoriamente, em 2005 os pescadores relataram ter menos dependência da atividade pesqueira, visto que diversificaram mais as atividades produtivas. Embora as diferenças tenham sido significativas entre os dois períodos, salienta-se que isto seja resultado de uma influência da abordagem da entrevista em campo sobre a resposta do pescador. Os entrevistados costumam demonstrar resistência a responder sobre atividades produtivas complementares, com receio de que os resultados da pesquisa afetem o acesso aos benefícios governamentais da pesca. Atividades secundárias à pesca são comuns, com o objetivo de promover o incremento na renda familiar (Capellesso \& Cazella, 2011; Faraco et al., 2016).

Nos últimos anos, outro recurso financeiro crescente no cenário da pesca artesanal é o proveniente do seguro defeso. Os pescadores do litoral paranaense também recebem este benefício, que alcançou $55,3 \%$ do total de pescadores em 2014. Este valor fica próximo da média nacional de $62,0 \%$ de beneficiados (Mendonça \& Lucena, 2013) e tem se tornado cada vez mais crescente a busca pelo benefício, haja vista que pode representar uma contribuição na renda familiar anual em média acima de 27,0\% (Mendonça \& Lucena, 2014). Este fato tem motivado a regularização de 
vários pescadores junto aos órgãos competentes, com obtenção da carteira de pescador e registro previdenciário, no MPA (atualmente no MDIC) e no Ministério da Previdência Social, respectivamente, mesmo que não façam da pesca sua principal atividade produtiva (Maia \& Pereira, 2010).

\section{Conclusões}

A pesca no litoral paranaense é de pequena escala, e envolve um contingente estimado de 5.752 pescadores, que mostraram aumento na idade média, possivelmente devido a menor entrada de novos pescadores na atividade ao longo dos 11 anos estudados.

Do ano de 2005 a 2015, houve uma diminuição da renda média dos pescadores, possivelmente devido: a) diminuição da produção dos pescados marinhos, que são alvos principalmente dos pescadores dos municípios de Pontal do Paraná, Matinhos e Guaratuba, na porção centro-sul do litoral paranaense; b) pelo menor crescimento do valor pago aos produtos pesqueiros de áreas estuarinas, alvos principalmente dos municípios de Guaraqueçaba, Antonina e Paranaguá, na porção centro-norte. Dado que, as diferenças na produção dos pescados marinhos e no valor pago nos estuarinos não parecem ter sido homogêneas, isso acarretou disparidade na renda média obtida pelos pescadores sediados em cada uma das porções do litoral.

A grande maioria dos pescadores está registrada (RGP), principalmente para ter acesso ao seguro defeso, que tem contribuído de forma significativa na renda familiar, principalmente dos pescadores do centro-norte.
A análise da evolução da pesca no litoral paranaense nos últimos 11 anos mostrou o setor em declínio, com diminuição da entrada de novos pescadores, aumento da idade média dos pescadores e o afastamento dos filhos à atividade. A descontinuidade pode ameaçar a sucessão da atividade, com efeitos sobre a perda de memória social e identidade, entre as quais, a transmissão entre gerações de conhecimentos e práticas sobre as técnicas de pesca desenvolvidas no litoral do Paraná.

Embora tenha ocorrido um encolhimento do setor pesqueiro no litoral paranaense, observa-se que a atividade ainda é um importante componente socioeconômico dos municípios. Ações são necessárias para promover a manutenção da pesca. Dada a longevidade da atividade pesqueira, em consonância com a manutenção da paisagem e qualidade dos ecossistemas, a manutenção dos modos de vida e a conservação da biodiversidade são objetivos plenamente alcançáveis.

\section{Agradecimentos}

Os autores agradecem a toda a equipe do projeto Caracterização socioeconômica da atividade pesqueira e aquícola nos municípios do litoral dos Estados de São Paulo e do Paraná, principalmente os técnicos Sérgio Cunha Xavier e Paulo Henrique Pontes Nepomuceno pela digitação das informações; a equipe de campo composta pelos agentes André Luiz M. Villar, Edison José Alves e Fabiano de Jesus Biscaia; e a toda a equipe de técnicos e estagiários do Instituto EMATER/PR e da Fundação Terra envolvidos nos trabalhos de campo do Censo da Pesca, realizado com recursos da Secretaria 
de Ciência e Tecnologia. Especial agradecimento à Fundação de Desenvolvimento da Pesquisa do Agronegócio pelos recursos financeiros para o desenvolvimento dos trabalhos em 2014 e 2015.

\section{Referências}

Anacleto, A.; Baptista-Metri, C.; Gonçalves, T. P.; Calado, A. M.; Rosário, E. S.; Pontes, M.; Neves, P. R. Extrativismo do siri com gaiolas no litoral paranaense: implicações socioeconômicas. In: Anais do XXXII International Sodebras Congress. Curitiba, PR, volume 10 (111): 9-14. Março/ 2015.

Andrew, N. L.; Béné, C.; Hall, S. J.; Allison, E. H.; Heck, S.; Ratner, B. D. Diagnosis and management of small-scale fisheries in developing countries. Fish and Fisheries, 8, 227-240, 2007.

Andreoli, V. M. Natureza e pesca: Um estudo sobre os pescadores artesanais de Matinhos - PR. Dissertação (Mestrado em Sociologia) - UFPR. 136p. 2007.

Andriguetto-Filho J. M.; Chaves, P. T.; Santos, C.; Liberati, S. A. Diagnóstico da pesca no litoral do estado do Paraná. In: Isaac, V. J.; Martins, A. S.; Haimovici, M.; AndriguettoFilho, J. M. (Orgs.). A pesca marinha e estuarina do Brasil no início do século XXI: recursos, tecnologias, aspectos socioeconômicos e institucionais. Universidade Federal do Pará, Belém, Brasil, p. 117-140. 2006.

Andriguetto-Filho, J. M.; Krul, R.; Feitosa, S. Analysis of natural and social dynamics of fishery production systems in Paraná, Brazil: implications for management and sustainability. Journal of Applied Ichthyology, 25, 277-286, 2009.

Barbetta, P. A. Estatística aplicada às Ciências Sociais. Ed. Da UFSC, $6^{\circ}$ ed. Florianópolis, 315p. 2006.

Berkes, F; Mahon, R.; Mcconney, P.; Pollnac, R.; Pomeroy, R. (autores da versão original em inglês). D. C. Kalikoski (Org. edição em português). Gestão da pesca de pequena escala: diretrizes e métodos alternativos. Ed. FURG, Rio Grande. 360p. 2006.
Borcem, E. R.; Furtado-Júnior, I.; Almeida, I. C.; Palheta, M. K. S.; Pinto, I. A. A atividade pesqueira no município de Marapanim-Pará, Brasil. Revista de Ciências Agrárias, 54(3), p. 189-201, 2011.

Borges, L. M. M.; Maulin, G. C.; Andriguetto, J. M. Analysis of Income Sources of Fishers' Families on the Coast of the State of Paraná, Brazil. Journal of Coastal Research, SI 39, 1267-1271, 2006.

Caldeira, G. A.; Pierri, N. As relações econômicas e a gestão compartilhada de recursos comuns: o caso da pesca marinha em Pontal do Paraná, Sul do Brasil. Desenvolvimento e Meio Ambiente, 32, 119-137, 2014.

Caldeira, G. A.; Mafra, T. V.; Malheiros, H. Z. Limites e possibilidades para a gestão participativa da pesca no litoral do Paraná, sul do Brasil: experiências do Projeto "Nas Malhas da Inclusão". Desenvolvimento e Meio Ambiente, 36, 331-353, 2016.

Callegari-Jacques, S. M. Bioestatística: princípios e aplicações. Porto Alegre. Ed. Artmed. 255p. 2004.

Controladoria Geral da União. Portal da Transparência da Presidência da República: beneficiados pelo programa de seguridade social dos pescadores artesanais. Disponível em: $<$ http://www.portaldatransparencia.gov.br/defeso/index. asp>. Acesso em: 02 maio 2016.

Capellesso, A. J.; Cazella, A. A. A pesca artesanal entre crise econômica e problemas socioambientais: estudo de caso nos municípios de Garopaba e Imbituba (SC). Ambiente \& Sociedade, 14(2), 15-33, 2011.

Castro, J. A. Evolução e desigualdade na educação brasileira. Educação \& Sociedade, 30(108), 673-697, 2009.

Diegues, A. C.; Arruda, R. S. V; Silva, V. C. F; Figols, F. A. $\mathrm{B}$; Andrade, D. Os saberes tradicionais e a biodiversidade no Brasil. In: Diegues, A. C. (Org.). MMA/COBIO e NUPAUB/USP, São Paulo, 211p. Fevereiro de 2000.

Diegues, A. C. Enciclopédia Caiçara - Festas, Lendas e Mitos Caiçaras. NUPAUB-CEC/HUCITEC Vol. 5, 414 p. 2006.

FAO - Food and Agriculture Organization. Putting into practice the ecosystem approach to fisheries. Rome, FAO. 76 pp. 2005. 
Faraco, L. F. D.; Andriguetto Filho, J. M.; Daw, T.; Lana, P. C.; Teixeira, C. F. Vulnerability Among Fishers in Southern Brazil and its Relation to Marine Protected Areas in a Scenario of Declining Fisheries. Desenvolvimento e Meio Ambiente, 38, 51-76, 2016.

Fuzetti, L.; Corrêa, M. F. M. Perfil e renda dos pescadores artesanais e das vilas da Ilha do Mel - Paraná, Brasil. Boletim do Instituto de Pesca, 35(4), 609-621, 2009.

Gomes, I. D.; Chaves, P. T. Ictiofauna integrante da pesca de arrasto camaroeiro no litoral sul do Estado do Paraná, Brasil. Bioikos, 20(1), 9-13, 2006.

IBGE - Instituto Brasileiro de Geografia e Estatística. Atlas do censo demográfico 2010 / IBGE - Rio de Janeiro: IBGE, 160p. 2013.

Jentoft, S.; Eide, A.; Bavinck, M. A Better Future: Prospects for Small-Scale Fishing People. In: Jentoft, S.; Eide, A. (Eds.). Poverty Mosaics: Realities and Prospects in SmallScale Fisheries. Springer Netherlands, Dordrecht, pp 451-469. 2011.

Mafra, T. V. Estratégias técnicas e econômicas dos sistemas de produção pesqueiros da região de Guaraqueçaba, litoral do Paraná. Dissertação (Mestrado em Meio Ambiente e Desenvolvimento) - UFPR, Curitiba, 228p. 2012.

Mahon, R.; McConney, P.; Roy, R. N. Governing fisheries as complex adaptive systems. Marine Policy, 32, 104-112, 2008.

Maia, M. B. R. Do defeso ao seguro desemprego do pescador artesanal: a inclusão do pescador nas políticas públicas de seguridade social. Dissertação (Mestrado em Sociologia) - UFA. Manaus. 106p. 2009

Maia, M. B.; Pereira, H. S. A inclusão do pescador nas políticas públicas de seguridade social do trabalhador rural. In: Encontro da Sociedade Brasileira de Sociologia, 2, Belém, 13-15/set./2010. Anais... Belém, UFPA, 1-15. 2010.

Mendonça, J. T. Caracterização da pesca artesanal no litoral sul de São Paulo, Brasil. Boletim do Instituto de Pesca, 41(3), 479-492, 2015.

Mendonça, J. T.; Lucena, A. C. P. Avaliação do seguro defeso concedido aos pescadores profissionais no Brasil. São Paulo. Série Relatórios Técnicos 50, 20p. 2013.
Mendonça, J. T.; Lucena, A. C. P. The impact of the insurance fishing closure on artisanal fishing of the south coast of São Paulo State (Brazil). In: Anais do Small-Scale Fisheries Congress - WSFC, 2, Merida, 21-26/set./2014. Anais... p.297-303. 2014.

MPA - Ministério da Pesca e Aquicultura. Cadastro dos pescadores com Registro Geral da Atividade Pesqueira $(R G P)$. Disponível em: http://www.sinpesq.mpa.gov.br/rgp Acesso em: 07 mar. 2013.

MEA - Millennium Ecosystem Assessment. Summary for decision makers. In Ecosystems and Human Well-being: Synthesis, 1-24. Washington, D.C.: Island Press. 2005.

Noernberg, M. A.; Angelotti, R.; Caldeira, G. A.; Sousa, A. F. R. Determinação da sensibilidade do litoral paranaense à contaminação por óleo. Brazilian Journal of Aquatic Science and Technology, 12, 49-59, 2008.

Pina, J. V.; Chaves, P. T. A pesca de tainha e parati na Baía de Guaratuba, Paraná, Brasil. Acta Biológica Paranaense, 34(1, 2, 3, 4), 103-113, 2005.

Possamai, B.; Carvalho, B. M.; Rosa, L. C.; Corrêa, M. F. M.; Dolci, N. N. Seletividade de armadilhas e engodos na captura de peixes e crustáceos na gamboa do Perequê, Paraná, Brasil. In: Anais do XIV Congresso LatinoAmericano de Ciências do Mar - XIV COLACMAR. Balneário Camboriú (SC / Brasil), 30 de outubro a 04 de novembro de 2011.

Silva, L. G. S. Caiçaras e Jangadeiros: cultura marítima e modernização do Brasil. Coord. Antônio Carlos S. Diegues. São Paulo: CEMAR/Universidade de São Paulo,145p. 1993.

Vasconcelos, E. M. S.; Lins, J. E.; Matos, J. A.; Júnior, W.; Tavares, M. M. Perfil socioeconômico dos produtores da pesca artesanal marítima do Estado do Rio Grande do Norte. Boletim Técnico-Cientifico do CEPENE, 11(1), 277-292, 2003.

Veloso, F. A Evolução Recente e Propostas para a Melhoria da Educação no Brasil. In: Bacha, E. L.; Schwartzman, S. (Orgs.). Brasil: a nova agenda social. Rio de Janeiro: LTC, pg. 215-253. 2011.

Vicent, A. C. J.; Meeuwiga, J. J.; Pajarob, M. G.; Perantec, N. C. Characterizing a small-scale, data-poor, artisanal 
Possamai, B.; Carvalho, B. M.; Rosa, L. C.; Corrêa, M. F. M.; Dolci, N. N. Seletividade de armadilhas e engodos na captura de peixes e crustáceos na gamboa do Perequê, Paraná, Brasil. In: Anais do XIV Congresso Latino-Americano de Ciências do Mar-XIV COLACMAR. Balneário Camboriú (SC / Brasil), 30 de outubro a 04 de novembro de 2011.

Silva, L. G. S. Caiçaras e Jangadeiros: cultura marítima e modernização do Brasil. Coord. Antônio Carlos S. Diegues. São Paulo: CEMAR/Universidade de São Paulo,145p. 1993.

Vasconcelos, E. M. S.; Lins, J. E.; Matos, J. A.; Júnior, W.; Tavares, M. M. Perfil socioeconômico dos produtores da pesca artesanal marítima do Estado do Rio Grande do Norte. Boletim Técnico-Cientifico do CEPENE, 11(1), 277-292, 2003.
Veloso, F. A Evolução Recente e Propostas para a Melhoria da Educação no Brasil. In: Bacha, E. L.; Schwartzman, S. (Orgs.). Brasil: a nova agenda social. Rio de Janeiro: LTC, pg. 215-253. 2011.

Vicent, A. C. J.; Meeuwiga, J. J.; Pajarob, M. G.; Perantec, N. C. Characterizing a small-scale, data-poor, artisanal fishery: Seahorses in the central Philippines. Fisheries Research, 86(2-3), 207-215, 2007. 